\title{
TESTEMUNHA DENTRO E FORA: VIOLÊNCIA, TRAUMA E MEMÓRIA EM MARTYRS (2008)
}

\author{
Silas Rodrigues Machado ${ }^{1}$ \\ Antonio Rediver Guizzo ${ }^{2}$ \\ Fernando Mesquita de Faria ${ }^{3}$
}

\begin{abstract}
Resumo: O presente estudo propõe discutir a relação entre o prazer e o horror do espectador diante da representação imaginária da violência a partir da análise do filme franco-canadense Martyrs (2008), do diretor e roteirista francês Pascal Laugier. Tal obra faz parte da nova safra de filmes franceses de horror que são caracterizados pela extrema violência e por roteiros que fogem dos clichês, no entanto, por vezes, caem despropositadamente na violência gratuita e outros problemas estruturais de enredo. Nessa perspectiva, analisa-se como a construção fílmica da obra contribui para a difusão do debate sobre violência, trauma e memória em produções culturais. Como aporte teórico, para desvendar o significado de alguns elementos do imaginário que compõe o filme, pautamos nos estudos de Gilbert Durand acerca das estruturas antropológicas do imaginário.
\end{abstract}

Palavras-chave: Martyrs; imagens de violência; filme de horror; imaginário; Gilbert Durand.

Abstract:This paper proposes to discuss the relationship between pleasure and viewer's horror in the face of violence imaginary representation in the French-Canadian film Martyrs (2008), directed and written by Pascal Laugier. This movie belongs a new generation of French horror films that are characterized by the extreme violence and scripts that avoid clichés. However, these movies sometimes fall unreasonably into the gratuitous violence representation and other structural plot problems. From this perspective, it is analyzed how Martyrs construction contributes for the diffusion of the debate on violence, trauma and memory in cultural productions. As a theoretical contribution, in order to analyses the imaginary elements that compose the movie, we base our studies into the Gilbert Durand researches on anthropological structures of the imaginary.

Keywords: Martyrs, images of violence, horror movie, imaginary, Gilbert Durand..

\footnotetext{
1 Mestre em Literatura Comparada (PPGLC) pela Universidade Federal da Integração Latino-Americana (UNILA).

E-mail: machadosilasr@gmail.com

2 Professor do Programa de Pós-Graduação em Literatura Comparada (PPGLC) da Universidade Federal da Integração Latino-Americana (UNILA).E-mail: antonio.guizzo@unila.edu.br

3 Professor do Programa de Pós-Graduação em Literatura Comparada (PPGLC) da Universidade Federal da Integração Latino-Americana (UNILA).E-mail: ferdi.faria@gmail.com
} 
Fotos fornecem um testemunho. Algo de que ouvimos falar, mas de que duvidamos parece comprovado quando nos mostram uma foto (SONTAG, 2004, p. 16).

A violência é um dos temas mais frequentemente abordados por imagens ao longo da história, passando desde as imagens gravadas em cavernas na Pré-história, pelos registros fotográficos e audiovisuais de guerras, até os filmes do século XXI. Porém, a violência foi e é representada com objetivos diversos: "como a mobilização popular, a crítica às investidas bélicas, o fortalecimento do ufanismo, o desenvolvimento do medo de punição, a obtenção de lucro etc" (RAMARI, 2014, p. 2). Dessa forma, apresentamos algumas considerações acerca do consumo de imagens de violência e da relação social de prazer e de horror decorrente de suas exposições.

A partir dessas considerações, elegemos como corpus de análise o filme de horror franco-canadense Martyrs (2008), do diretor e roteirista Pascal Laugier, por meio do qual buscamos compreender sua configuração estética, cuja constituição permeia questões que envolvem violência, trauma e memória. Como aporte teórico, para desvendar o significado de alguns elementos do imaginário que compõe a obra, pautamos nos estudos de Gilbert Durand sobre a composição, organização e funcionamento das estruturas antropológicas do imaginário.

\section{PRAZER E HORROR NO CONSUMO DE IMAGENS DE VIOLÊNCIA}

Em nossa "Era das Catástrofes", como a define Hobsbawm, a violência tornou-se um elemento constitutivo do campo político internacional - assistimos a duas guerras mundiais em um século e vivemos sobre a constante ameaça de uma guerra nuclear com potencial destrutivo inimaginável. Nesse contexto, seria oportuno refletir sobre como as imagens fotográficas e fílmicas das guerras - reproduzidas massivamente pelos meios de comunicação visual - promoveram (ou alimentaram) um interesse crescente da sociedade por imagens de violência.

Em relação às imagens fotográficas, Kátia Hallak Lombardi destaca que sua produção teve início quando Roger Fenton, em 1855, partiu com sua equipe de quatro assistentes, em uma carroça-laboratório, para fotografar os campos de batalha da Crimeia. Depois desse episódio, "a documentação fotográfica de conflitos e massacres tornou-se parte do fluxo incessante de imagens que circundam nosso cotidiano" (LOMBARDI, 2011, p. 15).

No entanto, conforme observa Lombardi, "as fotografias nada têm de inocentes, são recortes espaço-temporais configurados ideologicamente" (2011, p. 15). No caso das fotos encomendadas pelo governo britânico a Roger Fenton, por exemplo, fizeram com que a guerra parecesse não tão carregada de atrocidades. Corroborando as considerações de Lombardi, em uma dimensão semelhante, Susan Sontag (2003), em Diante da dor dos outros, evidencia que a criação de imagens por câmeras são consideradas mais verdadeiras quando não carregam o peso da intervenção artística: 
[...] as pessoas querem o peso do testemunho sem a nódoa do talento artístico, tido como equivalente à insinceridade ou à mera trapaça. Fotos de acontecimentos infernais parecem mais autênticas quando não dão a impressão de terem sido 'corretamente' iluminadas e compostas porque o fotógrafo era um amador ou o que é igualmente aproveitável - adotou um dos diversos estilos sabidamente antiartísticos. Ao voarem baixo, em termos artísticos, essas fotos são julgadas menos manipuladoras - hoje, todas as imagens de sofrimento amplamente divulgadas estão sob essa suspeita - e menos aptas a suscitar compaixão ou identificação enganosas (2003, p. 26-27).

Mas é somente a partir da guerra em que os Estados Unidos travaram no Vietnã - a primeira a ser monitorada dia-a-dia por parte das emissoras de televisão - que a intervenção estética na documentação visual de conflitos cai em desuso.

Desde então, batalhas e massacres filmados no momento em que se desenrolam tornaram-se um ingrediente rotineiro do fluxo incessante de entretenimento televisivo doméstico. Criar, para determinado conflito, um nicho na consciência de espectadores expostos a dramas de toda parte do mundo demanda uma difusão e redifusão diária de imagens filmadas desse conflito. A compreensão da guerra entre pessoas que não vivenciaram uma guerra é, agora, sobretudo um produto do impacto dessas imagens (SONTAG, 2003, p. 22).

Ademais, na atualidade, também observamos o consumo massivo das imagens de violência e a consequente banalização da própria violência. Para Maria Rita Kehl (2004), a humanidade hoje - por excelência por meio da filmografia norte-americana -, assiste a imagens cada vez mais violentas:

Com a exposição repetida às representações da violência, tendemos nos habituar e a tolerar cenas que nos horrorizariam há dez anos, há vinte anos. Hoje, assistimos tranquilamente a cenas que nos fariam sair da sala alguns anos atrás. [...] Vamos nos acostumando à violência, como se fosse a única linguagem eficiente para lidar com a diferença; vamos achando normal que, na ficção, todos os conflitos terminem com a eliminação ou a violação do corpo do outro (KEHL, 2004, p. 89).

Nessa perspectiva, principalmente no que se refere à produção hollywoodiana de filmes de horror, temos uma avalanche de fruições gratuitas de violência, isto é, representações fílmicas em que as cenas de violência extrapolam a função constitutiva do enredo e são reproduzidas simplesmente para atrair certo público às salas de cinema. Tais representações não suscitam nada além de um prazer sádico no espectador que se encontra fomentado e naturalizado pela própria produção massiva de tais obras.

Inserido no contexto das imagens de violência, temos a obra de horror Martyrs de Pascal Laugier. O filme é construído de maneira não convencional, utilizando uma estrutura narrativa que pode ser dividida em duas partes que transitam entre três subgêneros 
do horror. A primeira parte trabalha com dois subgêneros - assombração e vingança - e tem como protagonista a personagem Lucie, interpretada pela atriz Jessie Pham (criança) e pela Mylène Jampanoï (adulta); a segunda parte transita no subgênero tortura e a narrativa centra na personagem Anna, interpretada pela atriz Morjona Alaoui. Nas próximas seções, analisaremos as partes constitutivas do filme Martyrs e a configuração estética da violência representada nestas partes.

\section{PRIMEIRA PARTE: OS MOVIMENTOS CAÓTICOS}

O filme inicia com ruídos de porta batendo em um ambiente pouco iluminado, enquanto Lucie - filmada de costas para a câmera -, com uma respiração ofegante, aparece correndo com movimentos desgovernados. Sua imagem, repleta de movimentos de câmera, desfoques e mudanças de planos, revela-nos uma sincronia entre a câmera e Lucie, além de produzir a sensação de fuga. Na sequência, temos uma porta aberta que leva a saída de um edifício, marcando assim, o contraste entre a escuridão em que Lucie estava inserida e a luz do dia - a liberdade. Com planos alternados, entre primeiríssimo plano, plano próximo, plano médio e plano inteiro, podemos acompanhar a ambientação desértica da zona industrial onde ela se encontra como também a ênfase em sua expressão de desespero, seus muitos hematomas espalhados pelo corpo e seus ruídos, alternados entre gritos e gemidos.

A primeira sequência do filme dura menos de 30 segundos e a maioria de seus planos não passam de 4 segundos, exceto, o último que dura cerca de 7 segundos, ou seja, podemos entender como um chamado para dar maior atenção a esse quadro. Pois ora, se é a partir da guerra do Vietnã que o registro da violência começa a perder seu aspecto artístico e desencadeia um fluxo incessante de entretenimento televisivo pautado na violência, naturalizando assim, a forma como recebemos tais conteúdos, é possível que a escolha de dar destaque para tal quadro não seja apenas aleatória. Vejamos. Usar um plano inteiro, selecionar uma atriz com traços orientais, assim como sua movimentação desgovernada, leva-nos a crer que, não por acaso, faz referência à famosa fotografia de 1972 da menina do Vietnã de Huynh Cong "Nick" Ut, da Associated Press. Marcando assim, o eixo do debate:

Figura 1: Menina vietnamita (1972).

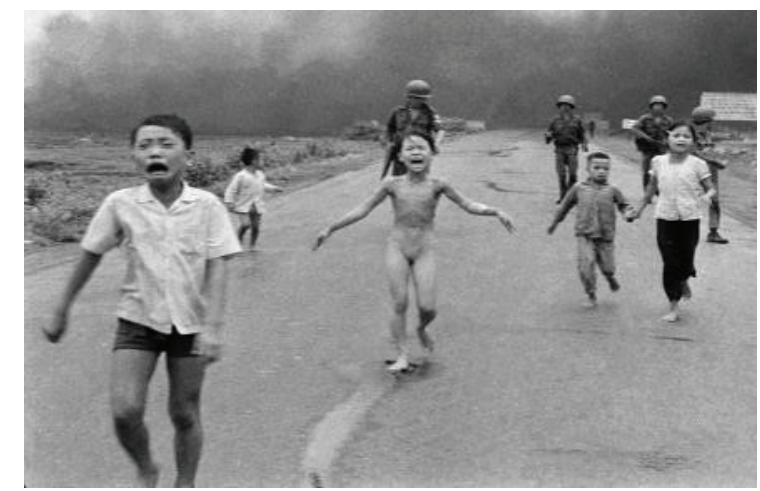

Fonte: World Press Photo - Nick Ut (1972). 
Figura 2: Lucie fugindo do cativeiro.

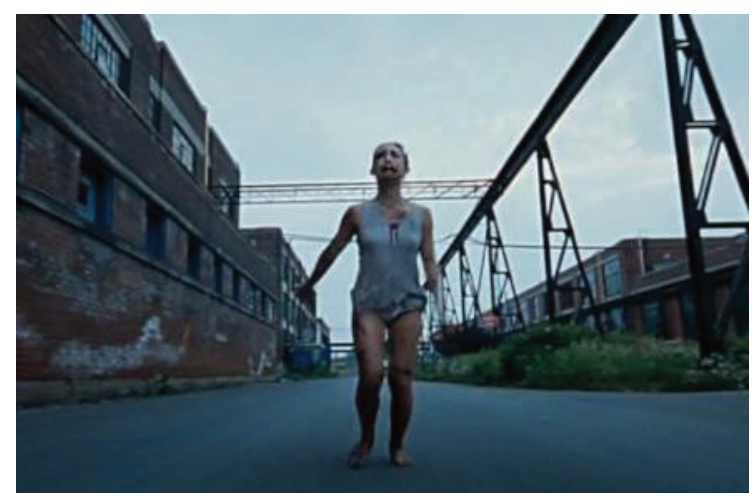

Fonte: Martyrs (2008).

$\mathrm{Na}$ sequência, Laugier novamente se utiliza de recursos que representa o registro da violência. Nesse caso, lança mão da metalinguagem para contar esse primeiro momento de Lucie. O psiquiatra da protagonista produz uma espécie de documentário que utilizará como registro médico para ala pediátrica, assim, começa a rodar o filme dentro do filme. O registro marca a data de 1971 e inicia-se com o movimento zoom in da câmera focando em Lucie acompanhada de um médico. Corte seco e por um plano médio, uma freira entrega uma bicicleta para Lucie. Zoom in em Lucie, corte seco e em plano geral conjunto, temos Lucie apresentando pequenos sintomas de trauma ao se assustar com uma bicicleta imóvel. Novamente um corte seco e em plano próximo, uma enfermeira aparece lendo uma notícia de jornal com a manchete "RETROUVÉE" e uma foto de Lucie - a presença de casos de atrocidades que se tornam entretenimento ganha voz de forma sútil nesse momento. O documentário segue apresentando o local onde Lucie ficou em cativeiro, pontua questões de como foi o procedimento - que não houve abusos, mas torturas e privações -, depois foca em momentos de Lucie na clínica, suas alucinações e sua dificuldade de se relacionar com as pessoas, exceto com Anna, em que começa a criar confiança. Assim, finaliza o registro.

No cotidiano da clínica, Lucie começa a ser assombrada por uma mulher que a flagela. Pascal Laugier monta uma narrativa que nos leva a crer que a obra caminharia para um filme de assombração como muitos outros em que um alojamento é atormentado por fantasmas. No entanto, o filme passa por sua primeira ruptura, pois abre espaço a um trhiller de vingança.

Temos uma clássica cena de família feliz de comercial de margarina. Com diálogos bem humorados e questões do cotidiano, como: a filha que apareceu no jornal por ser campeã de natação, o filho mais velho que não sabe muito bem o que fazer da vida ou mesmo, um cano entupido por um rato morto. Até que a campainha toca. Lucie, 15 anos após o evento traumático, entra na casa matando toda a família com uma espingarda. Essa cena é extremamente perturbadora e violenta pela forma tranquila com que a protagonista executa a família.

Conforme Gilbert Durand (2012), o aspecto temível do imaginário pode ser categorizado em três conjuntos simbólicos: a) os símbolos teriomórficos (ligados à animalidade); b) os símbolos nictomórficos (ligados às trevas e à noite), e c) os símbolos catamórficos 
(ligados ao movimento da queda). Sobre tal categorização, Strongoli (2005) ressalta que esses conjuntos simbólicos são originados da experiência empírica do homem com o mundo, logo, são revestidos de um realismo sensorial, associado ao movimento dos animais, a ausência de luz das trevas e a sensação de queda - "resultado do estímulo externo que norteia o processo de figurar o mal (o medo da passagem do tempo e dos diversos tipos de morte), não correspondendo à ação do indivíduo sobre o mundo, mas do mundo real e seus mistérios sobre o indivíduo" (STRONGOLI, 2005, p. 161).

Em confluência com o pensamento de Durand, observamos que os movimentos iniciais da câmera nesse segundo momento da primeira parte (a vingança) amplificam a subjetividade das interpretações. Os constantes movimentos desgovernados e as mudanças bruscas de ângulos e de distância em relação aos personagens parecem representar o próprio estado agônico de espírito da protagonista. Podemos notar tal movimentação da câmera em praticamente toda a primeira sequência (da vingança).

Analisando mais detidamente a sequência em que Lucie persegue a filha mais nova da família para melhor caracterização do movimento descrito, observamos que Lucie se encontra em plano inteiro em cima da cama prestes a atirar na menina. Corte seco para foco na arma seguida da câmera em movimento para foco em seu rosto. Corte para câmera plongé $e^{4}$ com foco na arma apontada para cama. Corte para foco na arma. Corte para plano inteiro de Lucie. Corte para foco na arma. Corte para câmera plongée em que Lucia atira na cama. Corte para plano inteiro seguido por um fervilhar de penas que se espalham por todo o quarto. A filha que se esconde debaixo da cama, grita. Corte e foco no rosto da menina. Corte para plano médio de Lucie recarregando a arma. Corte para foco na arma. Corte para o cartucho caindo na cama junto às penas. Corte para a menina. Corte para foco na arma seguido do movimento da câmera para o rosto de Lucie. Corte para plano inteiro. Corte para foco no rosto da menina saindo debaixo da cama. Corte para a menina de joelhos de costas para a câmera que levanta e corre em direção à porta. Corte para o rosto de Lucie. Corte para a menina em plano médio de frente para a câmera levando o tiro pelas costas. Corte para a menina de perfil em plano médio sendo atirada para frente com a violência do tiro. Corte para Lucie em plano inteiro em meio as penas se espalhando pelo quarto.

Com uma sequência de menos de 30 segundos, podemos notar a agitação caótica provocada pelos inúmeros cortes, pelo movimento da câmera e pelas penas. Essa animação se repete no auge da crise de Lucie quando, depois de executar sua vingança, encontra-se apenas entre silêncio e corpos. Ao olhar para o corpo sem vida da mulher que a torturou quando criança, Lucie começa a gritar e perguntar o motivo de tal ato. Resultando - em meio à euforia do movimento da câmera, dos cortes e dos gritos - em um disparo para cima. Neste momento, temos em plano geral externo, o movimento caótico de pássaros a alçar voo.

4 A câmara está posicionada acima do seu objeto, que é visto, portanto, em ângulo superior. 
Figura 3.

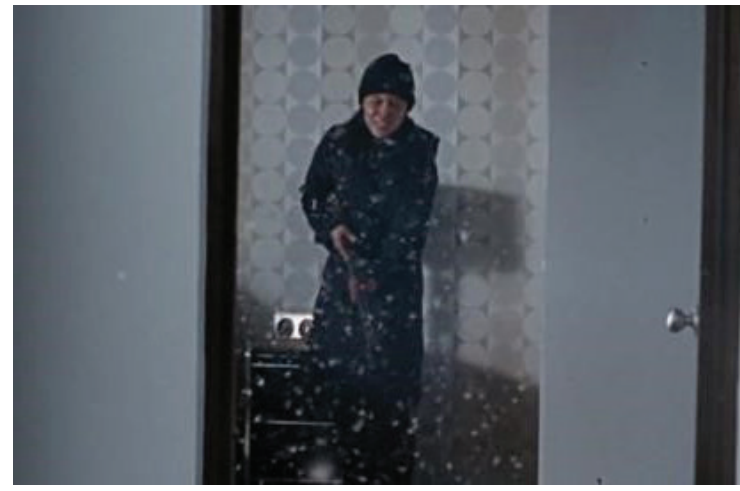

Figura 4.

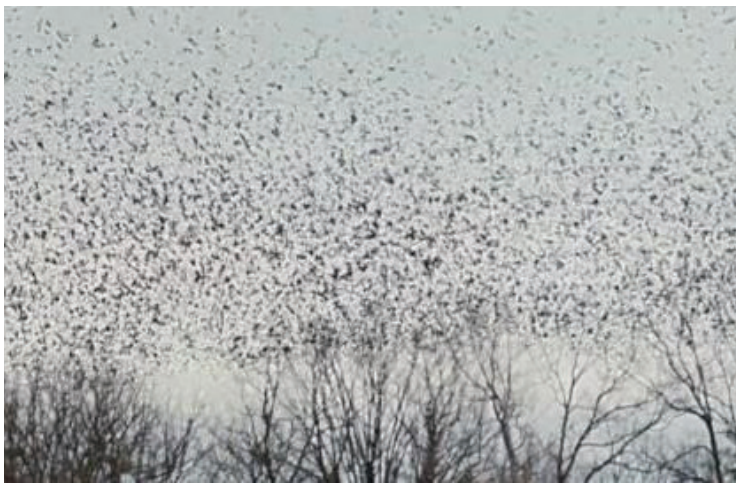

Fonte: Martyrs (2008).

Na cena descrita, observamos a confluência de símbolos teriomórficos, caracterizados pelo movimento, animação acelerada, agitação formigante, fervilhante, movimento desordenado que infere o arquétipo do caos, projeção da angústia diante da mudança, relacionada às primeiras experiências dolorosas da infância - manipulações da parteira, desmame, nascimento da primeira dentição (DURAND, 2012).

Vale notar que os subgêneros de horror trabalhados nessa primeira parte - vingança e assombração - intercalam-se. Depois de terminado o trhiller de vingança, volta-se a narrativa ao subgênero assombração. Neste, compreendemos que Lucie executou toda a família por acreditar que o fantasma da mulher nefasta não a machucaria mais. Entretanto, mesmo depois dos assassinatos, ela continua sendo atormentada pela entidade. $O$ foco narrativo volta-se à assombração que tem suas ações representadas por meio de movimentos desordenados e rastejantes.

Figura 5.

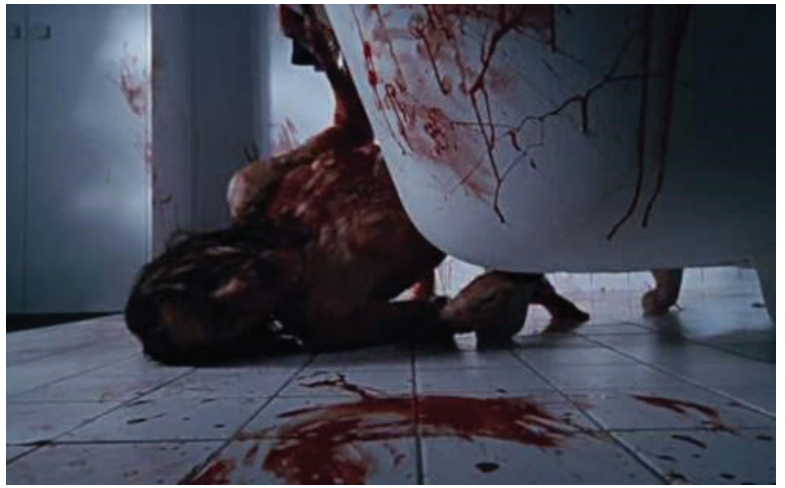

Fonte: Martyrs (2008).

Pascal Laugier leva o espectador a acreditar que a assombração persegue Lucie em busca de vingança ao inserir, na sequência, a personagem Anna, que descobre que a mulher que torturou a amiga ainda continua viva. Anna tenta esconder a mulher para que Lucie não a mate. Entre perseguições e fugas - seja Lucie fugindo da assombração ou Anna e a mulher fugindo de Lucie -, o filme entra em uma frenética sequência de ação que termina na morte da mulher que havia torturado Lucie. No entanto, a assombração continua perseguindo Lucie, o que nos leva a segunda ruptura da trama. 
Por meio de flashbacks, o espectador descobre que esta mulher - a assombração - era uma jovem que estava presa no mesmo cativeiro que Lucie, sofrendo as mesmas torturas, e também descobre que Lucie, ao fugir, ignora o pedido de ajuda dessa jovem. Além de contextualizar a origem da assombração, Pascal Laugier também desconstrói a ideia da mulher representar um espírito vingativo, pois, ao fazer com que a câmera assuma o olhar das personagens Lucie e Anna, vemos no ponto de vista de Lucie a assombração atacando-a e cortando seus pulsos, por outro lado, por meio do olhar de Anna, vemos Lucie autoflagelando-se e cortando os próprios pulsos.

Sendo assim, por meio do tratamento simbólico trabalhado por Pascal na construção da "assombração", compreendemos que todos os movimentos caóticos representam à própria esquizofrenia de Lucie. Isto é, a psique agônica de Lucie encontra nos símbolos teriomórficos a matéria para o imaginário que constitui a perseguição e a violência infligida pela assombração. Conforme Durand, "na maior parte dos casos, a animalidade, depois de ter sido símbolo da agitação e da mudança, assume mais simplesmente o simbolismo da agressividade, da crueldade" (2012, p. 84). Nesse sentido, podemos observar que o momento traumático vivido por Lucie, como também a culpa por ter abandonado a outra jovem no momento de fuga, é revivido por meio da representação de uma assombração que se movimenta como um animal repugnante. Do mesmo modo, a composição das cenas da vingança perpetrada por Lucie também são representadas por diversas técnicas que dão movimento caótico à narrativa fílmica, terminando com a cena do voo dos pássaros, durante a crise de Lucie pós-vingança, que mescla liberdade e desorientação.

A primeira parte termina quando Lucie percebe que não conseguiria se livrar da assombração - diga-se trauma - e descobre que sua amiga/protetora nunca havia acreditado nela, isto é, na narrativa da assombração e no relato das torturas sofridas. O fim da primeira parte é representado pela cena de Lucie cortando a própria garganta frente a tais desilusões.

\section{SEGUNDA PARTE: DESCIDA E TRANSMUTAÇÃO}

A ideia de redenção pelo sofrimento é e continuará a ser a maior ideia mágica do mundo moderno (MORIN, 1988, p. 199).

$\mathrm{Na}$ segunda parte, a narrativa centra-se em Anna, que encontra em um local secreto embaixo da casa uma mulher acorrentada e descobre que o relato de Lucie era verdadeiro. Anna tenta libertar a vítima, mas outros membros da "seita" chegam, juntamente com a líder, Mademoiselle. Neste momento, descobrimos que os membros da seita acreditam que certas pessoas conseguem, quando passam por uma situação de extrema violência e flagelo do corpo, entrar em uma nova dimensão de existência, transpondo o limite entre vida e morte e tornando-se mártires. Nas palavras de Mademoiselle:

É fácil criar uma vítima. Muito fácil. Você tranca uma pessoa num lugar escuro, ela começa a sofrer. Você nutre esse sofrimento. Lentamente. Metodicamente, sistematicamente, friamente. Por muito tempo. E então, o sujeito passa por dife- 
rentes etapas. Depois de algum tempo, o trauma. Aquela pequena fenda tão fácil de abrir, o fará ver coisas que não existem [...] As pessoas querem se livrar do sofrimento. O mundo chegou a um ponto em que só restam vítimas. Os mártires são raros. Um mártir é outra coisa. Um mártir é um ser excepcional. Sobrevive ao sofrimento e à privação de tudo. Carregam toda a maldade do mundo e, mesmo assim, ele transcende-se.

Aqui, Mademoiselle apresenta a definição de mártir da seita - alguém que sacrifica a vida por uma causa superior. Continuando o diálogo com o consumo de imagens de violência, Laugier utiliza novamente o recurso das fotografias. Mademoseille enfatiza uma apresentação de fotos a Anna, acentuando que as vítimas fotografadas ainda estavam vivas no momento em que as fotos foram tiradas. Representando o estado frio do fotógrafo diante da dor dos outros.

Figuras: 6.

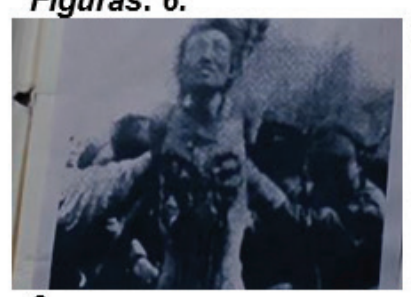

9.

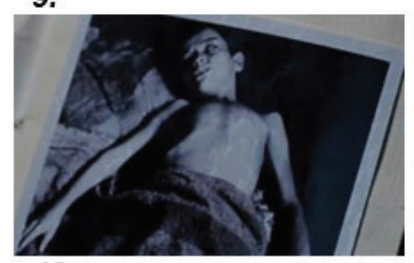

12.
7.

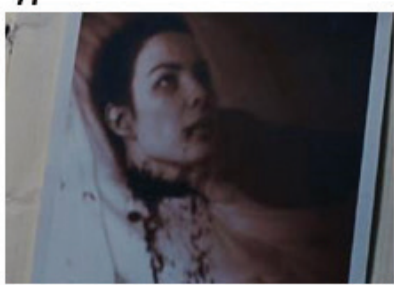

10.

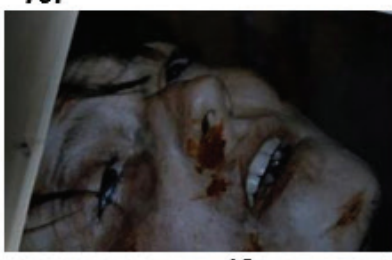

13.

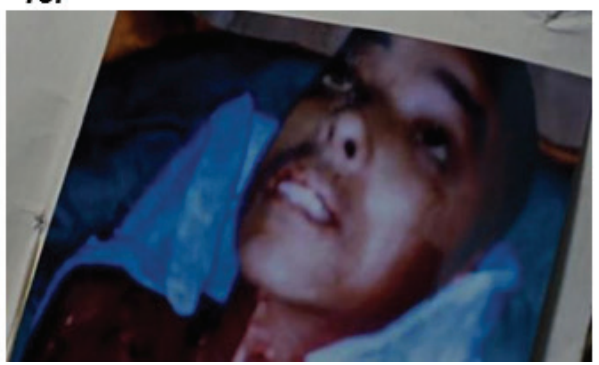

8.

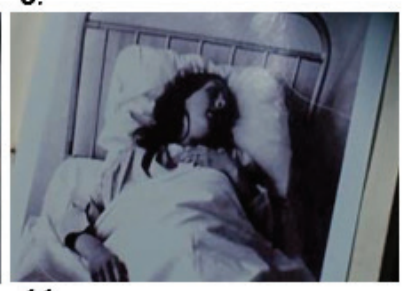

11.

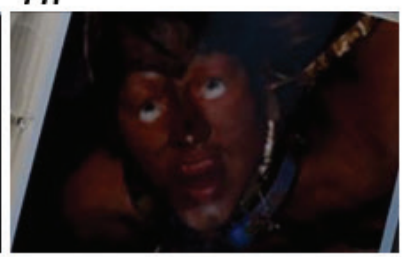

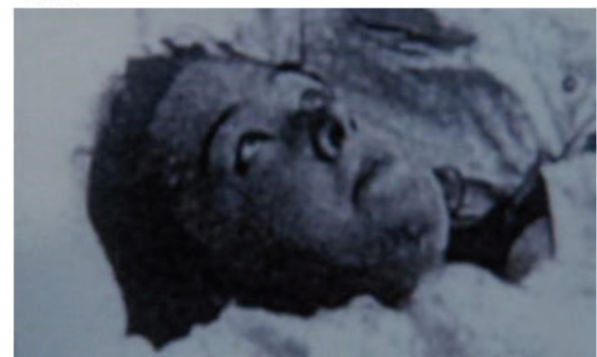

Fonte: Martyrs (2008).

Ainda no que cerne o consumo de imagens de violência, nada mais significativo do que o momento mais bárbaro da humanidade que foi documentado: o Holocausto. A escolha das duas protagonistas - uma de origem oriental e outra de origem marroquina -, como dos integrantes da seita - todos os membros possuem traços arianos - e a cena em que os integrantes da seita "despejam" o corpo sem vida de Lucie - enrolada em um pano branco numa vala - provocam no espectador o resgate da memória de características e imagens do Holocausto: 
Figuras: 14 .

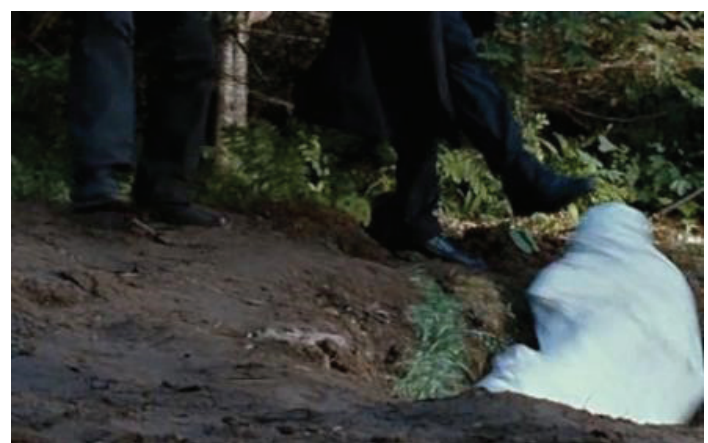

15.

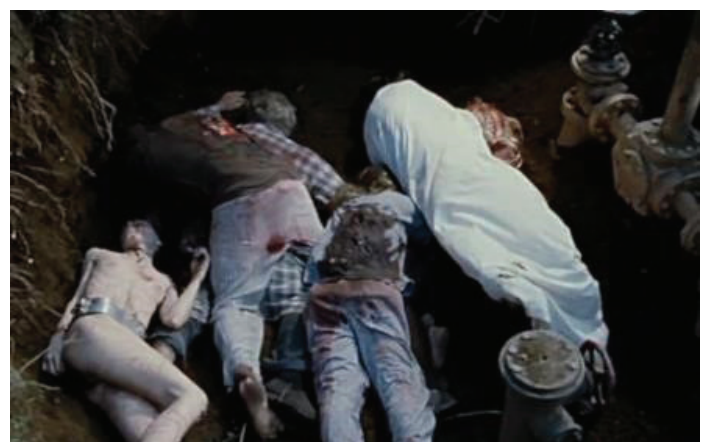

Fonte: Martyrs (2008).

16.

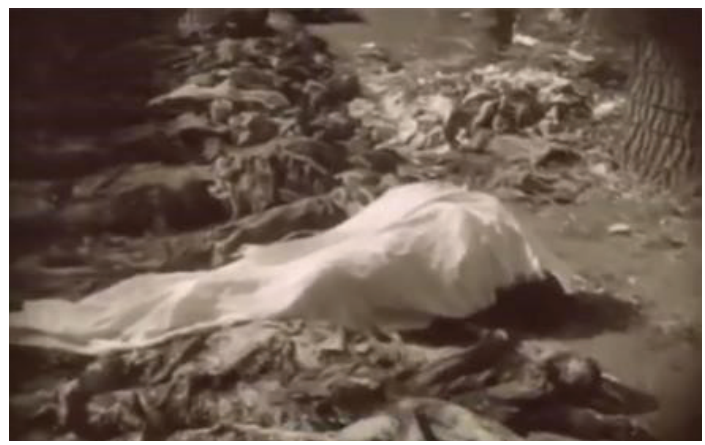

17.

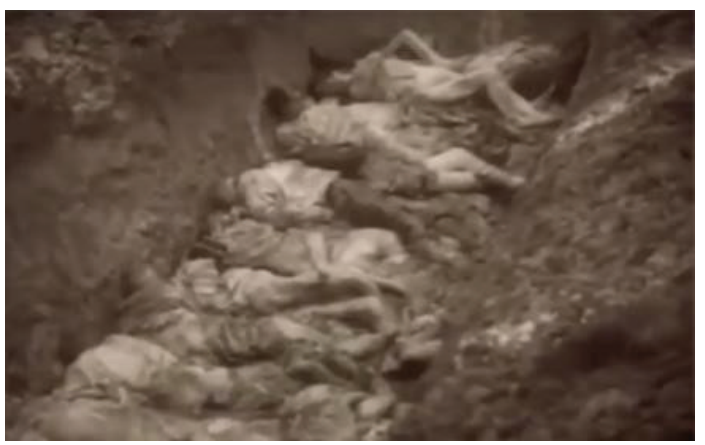

Fonte: Unseen Holocaust (2014).

Ademais, os membros da seita, da mesma forma que o nazismo buscava a constituição de uma "raça pura", pregam um estado "puro" de existência - o estado de elevação dos mártires. Dessa forma, a comparação com esse período da história é perfeitamente possível, principalmente, se levarmos em consideração as imagens destacadas que podem fazer referência ao momento de ocupação da Ucrânia em que mais de 5.000 judeus foram executados e seus corpos jogados em valas comuns.

De acordo com Huyssen, na década de 1980 - mesmo período do filme em que começa as referências ao nazismo - o Holocausto "perde sua qualidade de índice do evento histórico específico e começa a funcionar como uma metáfora para outras histórias e memórias” (2004, p. 13). Em um sentido semelhante, observamos que as referências ao Holocausto em Martyrs não são meramente ilustrativas, mas expressam o debate profundo em que o filme está inserido: a problemática busca de ressignificação da subjetividade contemporânea após o fim das utopias.

A personagem principal da primeira parte do filme, Lucie, é um tipo ideal, pois pode ser ligada a diferentes massacres, do Holocausto à Guerra do Vietnã. Tipo ideal pelo qual Laugier produz um terror que se conecta com os discursos de memória, ou seja, com a ressignificação da subjetividade contemporânea que marca a década de 1980.

$\mathrm{Na}$ sequência da narrativa, Mademoseille afirma que Lucie, no final das contas, era apenas mais uma vítima e faz Anna passar pelo mesmo processo de sofrimento e privação, 
dando início ao momento mais violento do filme. Nesta segunda parte, além de mudar o ritmo, o gênero, o movimento da câmera e a protagonista, os símbolos que aparecem se referem a outro regime simbólico do imaginário humano a que Gilbert Durand denomina Regime Noturno da Imagem.

Os símbolos presentes nesse regime são caracterizados pelo movimento de inversão da polaridade (do negativo ao positivo); portanto, estão sob o signo da conversão e do eufemismo. Eufemização que "faz-se sempre com prudência, por etapas, de tal modo que as imagens conservam, apesar de uma forte intenção de antífrase, um traço da sua origem terrificante" (DURAND, 2012, p. 199).

Primeiro, veremos as imagens que diz respeito à descida. Em consonância com Durand (2012, p. 201), é fácil conceber que nas profundidades obscuras e escondidas - em nosso caso, no próprio interior das vítimas -, o limite entre o ato temerário da descida sem guia e a queda nos abismos animais, seja pequeno. Dessa forma, "a descida arrisca-se, a todo o momento, a confundir-se e a transformar-se em queda” (2012, p. 201).

O processo de eufemização das imagens pode ser observado na sequência de tortura. A primeira coisa que podemos notar é o tempo, todo o período de martirização de Anna tem cerca de 25 minutos, que poderia muito bem deixar o espectador exausto diante de tanta violência. No entanto, as imagens de conversão trabalhadas por Laugier são essenciais para amenizar o impacto das cenas, transformando, lentamente, uma simbologia relacionada à "queda" (degradação física e moral) em descida (aceitação). Nessa perspectiva, temos um primeiro momento marcado pela tortura quase ritualística de Anna - com duração de 13 minutos -, nesta sequência, a protagonista parece ser "domesticada", perdendo, gradualmente, toda sua forma de reação. Por exemplo, a protagonista é alimentada por um dos membros da seita, este, coloca um tipo de comida pastosa em sua boca - substituindo o ato de mastigar por engolir, ato que no imaginário, conforme Durand, substitui a agressividade da mastigação pela imagem eufemizada do engolimento, análoga à eufemização da descida. O mesmo ocorre quando ela é desacorrentada para apanhar, substituindo a reação e a procura de fuga pela "aceitação" da condição de tortura.

No segundo momento da tortura, todo o ruído de correntes, gritos, gemidos, ou mesmo sons desorganizados e estridentes, característicos de filmes de horror, deixam a cena para entrar uma melodia cíclica. Para Durand, o "simbolismo da melodia é [...] o tema de uma regressão às aspirações mais primitivas da psique, mas também o meio de exorcizar e reabilitar por uma espécie de eufemização constante a própria substância do tempo" (2012, p. 225). Dessa forma, Anna, frente a frente com a dor, opera pouco a pouco a inversão dos valores, transformando o ambiente de extrema violência externo em "quietude" e "assentimento" interno. Nesta sequência, ela permanece de olhos fechados, ao invés de resistir - como fazia até então -, ela começa a se acariciar com a pouca coordenação que ainda lhe resta e a resmungar como se estivesse falando consigo mesma. Entretanto, o ponto alto para a inversão dos valores que, de acordo com Durand, é essencial para distinguir a queda da descida, é a presença de um mentor. Conforme o antropólogo francês, a descida necessita de mais precaução que a ascensão e, frequentemente, é acompanhada por personagens que exercem a função de auxiliares no imaginário. Neste caso, ganha voz de sua amiga Lucie. Vejamos: 
“- Anna. Você está aí?

- Estou aqui.

- Anna?

- Sim, Lucie?

- Por que você nunca tem medo?

- As vezes tenho medo.

- Não como eu.

- Não passaria pelas mesmas coisas que você.

- O que tenho que fazer para não ter medo?

- Acho que você tem que se deixar levar.

- Você acha isso?

- Deixe se levar.

- Se eu não conseguir estará lá comigo?

- Sim."

Nesse sentido, este "desprender-se do medo" na trajetória figurativa da personagem é acompanhado da sonoridade musical, vivenciada "como fusão, comunhão do macro e do microcosmo" (DURAND, 2012, p. 225) e da voz de sua mentora, invertendo, assim, a valoração imaginária diante do tempo e da morte.

Outra inversão imaginária que pode ser observada nessa passagem narrativa é o fato de Laugier romper com a ideia do olhar para o alto do mártir enquanto elevação - símbolo frequentemente presente na figuração cristã da santidade, olhar que encaminha do terreno ao divino. No filme, esse olhar para o alto se torna um olhar para dentro, uma descida mais profunda ao interior - paradoxalmente, no Regime Noturno, "desce-se para subir no tempo e reencontrar as quietudes pré-natais” (DURAND, 2012, p. 203).

Nessa perspectiva, quando Anna é escalpelada para entrar num estado de quase morte, ela não ascende aos céus, mas desce, lentamente, ao absoluto dentro de si, transmutando o sofrimento do corpo em um estado que supera a dor, marcado por uma expressão de relaxamento, como se estivesse regressado ao útero da mãe. Tal ideia é trabalhada por Laugier ao focar o olhar de Anna que, como todos os outros mártires, estava para cima, no entanto, com um movimento zoom in da câmera, gradualmente, vai descendo ao seu interior.

Figuras: 18.

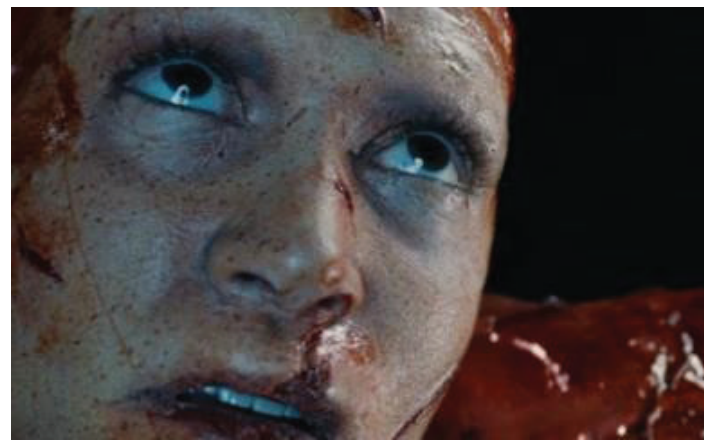

19.

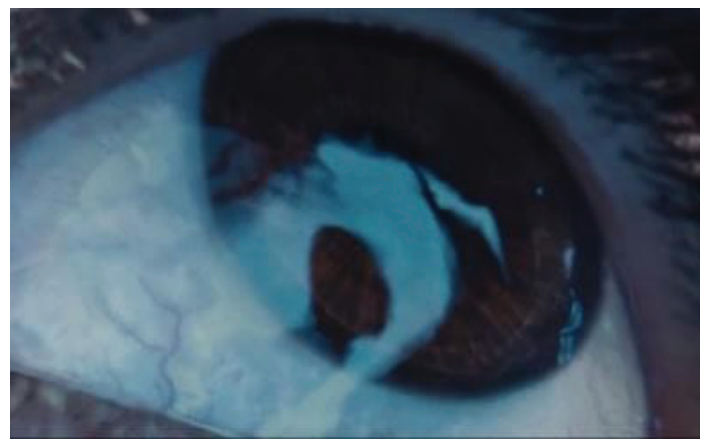

Fonte:Martyrs (2008). 
Figuras: 20.

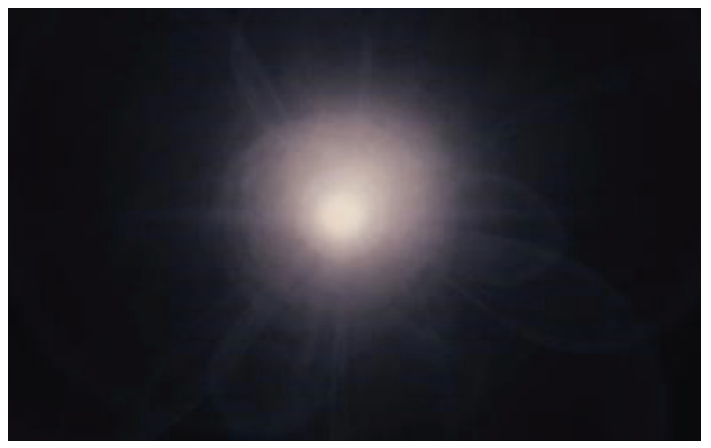

21.

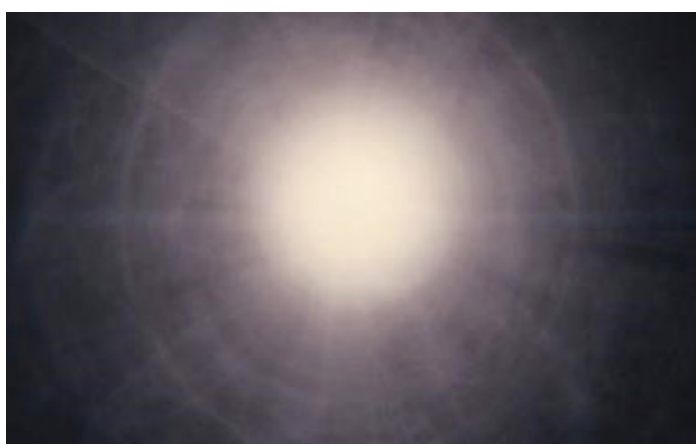

Fonte:Martyrs (2008).

Toda a cena da descida, sem cortes, dura 1"10 segundos, corroborando a ideia que já vimos da necessidade de lentidão para distinguir a descida da queda e da ascensão: “[...] o que distingue afetivamente a descida da fulgurância da queda, como de resto do levantar voo, é a sua lentidão. A duração é reintegrada, domesticada pelo simbolismo da descida graças a uma espécie de assimilação, por dentro, do devir" (DURAND, 2012, p. 201).

A inversão de polaridade do regime noturno da imagem torna-se essencial para essa primeira compreensão dos mártires, ou seja, da violência “justificada” em busca de um bem maior; e a construção de imagens realizada por Laugier leva o espectador a experienciar as atrocidades com tom mais ameno. Nas duas partes do filme, o diretor constrói cenários diversos para depois desconstruir e surpreender o público. Tendo em vista tal estratégia, Laugier surpreende novamente ao trazer um final aberto a interpretações, pois, logo depois de Anna confidenciar a Mademoiselle o que presenciou em seu estado martirizado (confissão só ouvida por Mademoiselle), a líder da seita tranca-se em um quarto e atira na própria boca sem contar a ninguém o que Anna sussurrara a ela. Em seguida, aparece um fundo preto com a origem etimológica grega da palavra mártir, que quer dizer, apenas, testemunha - sem toda a carga adquirida ao longo da história.

Dessa forma, Pascal realiza sua última ruptura na narrativa. Se até o momento, por meio do significado comum presente no imaginário da palavra mártir, a obra nos conduz a fazer uma leitura da redenção pelo sofrimento ou, ampliando a outros elementos, da violência “justificada” para alcançar um bem maior - como o cristianismo em nome da fé, o nazismo em nome da purificação da raça etc. Agora, Laugier traz à obra dois tipos de testemunha: a primeira diz respeito ao próprio universo do filme e a segunda, refere-se à experiência cinematográfica do espectador como testemunha.

A testemunha representada no filme é a que passa por extrema dor e privação em que sua principal "função" é fazer um relato do outro lado da vida, mas que nós, enquanto espectadores, somos privados de tal relato, seja pelo silêncio que temos quando Anna conta para Mademoiselle ou, seja pela decisão de Mademoiselle de levar o relato para o túmulo, tirando sua própria vida.

Em relação ao problema em questão, como salientamos no começo do texto, a forte presença da violência, principalmente na televisão, a partir da guerra que os Estados Unidos travaram com o Vietnã, apresentou à população civil norte-americana a nova teleintimi- 
dade com a morte e a destruição. Dessa forma, transformou o registro de massacres e de batalhas em entretenimento televisivo (SONTAG, 2003, p. 22). Nessa perspectiva, mesmo quem não presenciou fisicamente a nenhum momento de extrema violência, tem a sensação de ser testemunha pelo impacto do consumo dessas imagens.

Tal relação nos leva à revisão crítica o papel do espectador/testemunha na obra fílmica de Pascal. Este se depara com o silêncio do relato de Anna. O que deveria ser o grande momento do filme, a catarse que "justificaria" toda a violência em tela, transforma-se apenas em questionamentos. Essa ausência de catarse causa um desconforto muito maior no espectador naturalizado com a violência manifesta em cenas de tortura e de morte por serem “justificadas" pela construção de um "sentido superior". Ou seja, tal espectador, que busca apenas um filme de violência gratuita com respostas fáceis das quais acredita ser testemunha, é encurralado e levado a refletir sobre o trauma da tortura sem o apoio de um "motivo" testemunhável.

\section{CONSIDERAÇÕES FINAIS}

É possível observar que atualmente temos novas escritas de imagens de violência capazes de suscitar questões relacionadas às barbaridades dos conflitos no mundo contemporâneo. É nesse sentido que acreditamos que Pascal Laugier apresenta sua obra, mostrando "uma imagem menos atrelada à noção de testemunho" (LOMBARDI, 2011, p. 22) e que também, sua objetividade, pode conter "traços que nos levem a refletir sobre conflitos passados que estão na iminência do desaparecimento" (2011, p. 22).

Martyrs (2008) não é apenas um filme que banaliza a violência, mas sim, um resgate crítico do trajeto do consumo de imagens de violência, seja ligado ou desligado da arte, contribuindo para a reformulação da escrita de violência no cinema. Para corroborar tal compreensão podemos assinalar o remake hollywoodiano de 2015 que, apesar de ter o enredo semelhante, sem a construção fílmica orientada pela exploração do imaginário e sem as referências históricas, perde o sentido apresentado por Laugier em 2008. Tornando-se uma espetacularização superficial da violência, um mero produto genérico da indústria do horror.

\section{REFERÊNCIAS BIBLIOGRÁFICAS}

DURAND, Gilbert. As estruturas antropológicas do imaginário. São Paulo: Wmf Martins Fontes, 2012.

HUYSSEN, Andreas. Seduzidos pela Memória: arquitetura, monumentos, mídia. Rio de Janeiro: Aeroplano, 2004.

KEHL, Maria Rita. Televisão e violência do imaginário. In KEHL, Maria Rita; BUCCI, Eugênio. Videologias: ensaios sobre televisão. São Paulo: Boitempo, 2004, p. 87-106. 
LOMBARDI, Kátia Hallak. Fotografias de conflito: o que permanece? Discursos fotográficos, Londrina, v. 7, n. 11, p. 14-32, 2011.

MORIN, Edgar. O Homem e a Morte. Mem Martins: Publicações Europa-América, 1988.

RAMARI, Thiago Henrique. A violência na berlinda: o counter-cinematic de Michael Haneke. In Encontro Nacional de Pesquisa em Comunicação e Imagem, 2014, Londrina. Anais. 2014.

SONTAG, Susan. Diante da dor dos outros. São Paulo: Companhia das Letras, 2003.

SONTAG. Susan. Sobre fotografia. São Paulo: Companhia das Letras, 2004.

STRONGOLI, Maria Thereza de Queiroz Guimarães. Encontros com Gilbert Durand: Cartas, Depoimentos e Reflexões sobre o imaginário. in: PITTA, Danielle Perin Rocha (org.). Ritmos do Imaginário. Recife: Ed. Universitária da UFPE, 2005.

\section{REFERÊNCIAS FÍLMICAS}

Unseen Holocaust. Direção: IMC Vision. EUA, 2014. 78 min.

Martyrs. Direção: Pascal Laugier. The Weinstein Company. França/Canadá, 2008. 99 min.

Martyrs. Direção: Kevin Goetz, Michael Goetz. Anchor Bay Films. EUA, 2015. 86 min. 
